\title{
Investigation on influence of thermal barrier coating on diesel engine performance and emissions in dual-fuel mode using upgraded biogas
}

\author{
Shakti Prakash Jena and Saroj Kumar Acharya*
}

\begin{abstract}
In the present investigation, we used semidried banana leaves to produce biogas through anaerobic digestion where the methane content in biogas reached up to $87 \%$ via a scrubber fabricated with packed bed iron chips for removal of carbon dioxide and hydrogen sulphide. The diesel engine was converted to run in dual-fuel mode under variation of biogas flow rate at different engine loads. Yttria stabilized zirconia was used as thermal barrier coating (TBC) on piston crown and valves to improve the performance of dual-fuel engine. It was observed that engine with TBC has shown an improved combustion and performance characteristics for dual-fuel operation with reduction in exhaust emissions. The brake thermal efficiency at full load operation is decreased by 23, 29 and 34\% for uncoated engine with induction of biogas at $0.6,0.8$ and $1 \mathrm{~kg} \mathrm{~h}^{-1}$, respectively, while this decrease is minimized to 10,12 and $19 \%$ for coated engine at the corresponding flow rates with respect to base result. In uncoated engine the carbon monoxide emission at highest engine load is increased by 35,35 and $40 \%$ of the respective biogas flow rates, while in coated engine, the percentage of increase is reduced to 25,28 and $33 \%$ as compared to diesel mode operation. Similar trends were observed for unburnt hydrocarbon emissions, while nitric oxide emissions increased for coated engine in both modes of operation.
\end{abstract}

Keywords: Banana leaves, Scrubber, Biogas, Dual fuel, Coating

\section{Introduction}

Developing countries in the world including India are currently facing three important problems; increasing energy demand, increased environmental pollution and waste disposal. Due to increase in population, industrialization and improved lifestyle, it leads to hike in energy demand. Simultaneously, compression ignition (CI) engines are employed as the main life line of human beings for transportation, construction, irrigation and small-scale power generation [1-3]. In the present scenario most of the CI engine runs with fossil fuel which is depleting at a faster rate, leading to researchers for development and dissemination of renewable energy resources to incorporate as a substitute for fossil fuel [4]. In this context, dual-fuel

\footnotetext{
* Correspondence: saroj.acharya76@gmail.com

Department of Mechanical Engineering, Siksha 'O' Anusandhan Deemed to be University, Bhubaneswar 751030, India
}

mode diesel engines running with biogas can be considered as panacea to the above said problem.

Many researchers have experimented with various dual-fuel mode CI engine using biogas. For example, Duc and Wattanavichien [5] conducted an experiment to understand the consequence of biogas induction on the performance and emission parameters of $\mathrm{CI}$ engine. They found higher carbon monoxide (CO), unburnt hydrocarbon $(\mathrm{HC})$ emissions with increased specific energy consumption in dual-fuel mode. Diesel substitutions about $43-49 \%$ at full load operation were recorded. Makareviciene et al. [6] observed an increased $\mathrm{CO}$ and $\mathrm{HC}$ emissions with a drop-in brake thermal efficiency (BTE) in dual-fuel engine with biogas. Bora et al. [2] evaluated the consequence of change in compression ratio on performance of biogas operated dual-fuel engine. BTE increased with increase in compression ratio or $20.0,18.3,17.1$ and $16.4 \%$ at compression ratios of 18 ,

(c) The Author(s). 2019 Open Access This article is distributed under the terms of the Creative Commons Attribution 4.0 International License (http://creativecommons.org/licenses/by/4.0/), which permits unrestricted use, distribution, and 
17.5, 17 and 16, respectively. Tippayawong et al. [7] carried on experimentation on a small-scale $\mathrm{CI}$ engine using biogas for long term operation test. They observed minor piston wear that is not significant enough for deterioration of the engine performance in long term operation. Ambarita [8] carried out experiment on CI engine using biogas as inducted fuel with $70 \%$ methane content and achieved up to $87.5 \%$ diesel saving. Barik and Murugan [9] used biogas in a CI engine and observed decreases in oxides of nitrogen $\left(\mathrm{NO}_{\mathrm{x}}\right)$ and smoke emissions with an increase in $\mathrm{HC}$ and $\mathrm{CO}$ emissions along with a drop in thermal efficiency by $6.2 \%$. Barik and Murugan [10] also performed experimentation with advanced injection timing of pilot fuel and observed improvement in both performance and emission characteristics as compared to standard injection timing $23^{\circ}$ before top dead centre (TDC). Verma et al. [11] studied the impact of percentage of methane on dual-fuel performance with three different composition of biogas. Biogas with $93 \%$ of methane showed comparable result as that of diesel mode operation.

Performance improving techniques are required to get better performance of dual-fuel engines. Researchers have employed thermal barrier coating (TBC) to amplify the heat insulation within the combustion chamber resulting in the rise in combustion temperature and hence improving the performance and emission characteristics. Aydin et al. [12] employed TBC on engine piston and valve with composition $88 \%$ of zirconium oxide, $4 \%$ of magnesium oxide and $8 \%$ of aluminium oxide to improve the performance of diesel engine using biodiesel produced from cotton seed oil. Coated engine (CE) has showed improved BTE with reduced $\mathrm{HC}$ and $\mathrm{CO}$ emissions, while $\mathrm{NO}_{\mathrm{x}}$ emissions were increased as compared to uncoated engine. Jena et al. [13] investigated the effect of Yttria stabilized zirconia (YSZ) coating on engine performance and emissions. Ferric chloride $\left(0.2 \mathrm{~g} \mathrm{~L}^{-1}\right)$ used as additive with diesel in the CE improved BTE by $2.7 \%$ and decreased the emissions such as $\mathrm{HC}, \mathrm{CO}$ and smoke opacity except nitric oxide (NO) emission. Sivakumar and Kumar [14] carried out experiment on diesel engine with YSZ coating and observed $3-5 \%$ boost in brake power with a decrease in fuel consumption, $\mathrm{HC}$ and $\mathrm{CO}$ emissions. Mohapatra et al. [15] performed experiment on YSZ coated diesel engine along with steam injection. The BTE increased with decrease in NO emissions as compared to $\mathrm{CE}$ without steam injection.

In the present work we choose biogas from anaerobic digestion of semidried banana leaves with purification of biogas via a scrubber fabricated with packed bed iron chips for $\mathrm{H}_{2} \mathrm{~S}$ removal. Detailed descriptions of the biogas generation methodology and observed results of laboratory scale experimentation have been documented by the authors in the previous article [3]. The properties and calorific values of the upgraded biogas (UBG) are presented in Table 1 . A $3.5 \mathrm{~kW}$ diesel engine modified to dual-fuel mode and experiments were conducted with different flow rates of purified biogas under variation of engine loads. Base piston and valves are replaced with YSZ coated piston and valves, and then same experimentation was performed to explore the impact of TBC on dual-fuel performance.

\section{Experimentation}

The current experimentation is planned to use upgraded biogas in a dual-fuel $\mathrm{CI}$ engine with $\mathrm{TBC}$ to observe the variation in its performance, combustion and emission parameters.

\section{Development of CE}

Thermal spraying technique can be performed by different methods such as chemical deposition, plasma arc, physical vapor deposition, and atmospheric plasma spray method. Out of which plasma spray technique provides high porosity in the coated layer, makes it an ideal choice for TBC on the selected components of the engine. In plasma spray technique, powder ceramic is injected into a very high temperature plasma flame, where it is rapidly heated and accelerated to a high velocity spray to form the coating on the substrate. Argon or hydrogen or nitrogen gases was used as carrier gas, which minimizes the oxidation problem during coating process. To achieve the same compression ratio with coated components, the piston crown and valves were ground to $0.5 \mathrm{~mm}$ thickness. Then these components were undergone through blasting with alumina grits to improve the mechanical grip between sprayed materials and the substrate material. A commercially available NiCrAlY powder (H.C. Starck, Germany) of $0.1 \mathrm{~mm}$ thickness was deposited as bond coat by an $80 \mathrm{~kW}$ atmospheric plasma spray system (Metallisation, UK) on piston crown and valves of the selected engine using PS50 plasma torch. Then the powder ceramic $8 \mathrm{YSZ}\left(\mathrm{ZrO}_{2}-8 \mathrm{wt} \% \mathrm{Y}_{2} \mathrm{O}_{3}\right)$ was sprayed on the piston crown and valves surface to form a $0.4 \mathrm{~mm}$ thin top coat. The spray parameters of the coating synthesis are presented in Table 2 .

\section{Experimental setup}

A single cylinder, 4 stroke $\mathrm{CI}$ engine with power $3.5 \mathrm{~kW}$ at $1500 \mathrm{rpm}$ was used to run in dual-fuel mode. The inlet manifold was elongated by $91 \mathrm{~cm}$ where the biogas

Table 1 Compositions and calorific value of UBG

\begin{tabular}{ll}
\hline Gas Constituents & Volume (\%) \\
\hline $\mathrm{CH}_{4}$ & 87.0 \\
$\mathrm{CO}_{2}$ & 4.8 \\
$\mathrm{H}_{2}$ & 1.1 \\
Calorific value, MJ kg & -1 \\
\hline
\end{tabular}


Table 2 Plasma spray parameters

\begin{tabular}{|c|c|c|}
\hline Parameters & Bond coat (NiCrAlY) & Top coat $\left(\mathrm{ZrO}_{2}-8 \mathrm{wt} \% \mathrm{Y}_{2} \mathrm{O}_{3}\right)$ \\
\hline (A) & 500 & 450 \\
\hline$V(V)$ & $32-35$ & $50-60$ \\
\hline$P(k W)$ & $17-17.5$ & $23-23.5$ \\
\hline Primary gas flow rate (Ar) (slpm) & 40 & 40 \\
\hline Secondary gas flow rate $\left(\mathrm{H}_{2}\right)$ (slpm) & $\mathrm{Nil}$ & 0.2 \\
\hline Carrier gas flow (Ar) (slpm) & 5 & 5 \\
\hline Powder feed rate (rpm) & 10 & 10 \\
\hline Spraying distance (in cm) & 10 & 10 \\
\hline
\end{tabular}

injector was drilled into the intake manifold. For measurement of in-cylinder pressure, a piezo sensor (PCB Piezotronics, Depew, NY) with range of $34.5 \mathrm{MPa}$ was employed. A Kubler (Germany) made digital rotary encoder was used to measure the engine rpm. The complete specification of the engine is presented in Table 3. Software package "Engine SoftLV" of version 9 was employed for online performance and combustion analysis. The exhaust emissions were measured by online AVL-444 model (India), a multi-gas analyzer to measure $\mathrm{CO}, \mathrm{HC}, \mathrm{CO}_{2}$ and $\mathrm{NO}$ composition in the exhaust gas. To measure smoke opacity, AVL-437 model smoke meter (measuring range 0 to $100 \%$ with resolution $0.1 \%$ and uncertainty of \pm 1 ) was incorporated at the exhaust manifold. A computerized data acquiring device was used for documentation and analysis of experimental data.

\section{Experimental procedure}

The block diagram of the dual-fuel engine setup is presented in Fig. 1. The engine was run with diesel and readings were taken for base results after reaching steady state. In dual-fuel operation, biogas was inducted at three different flow rates $\left(0.6,0.8\right.$ and $\left.1 \mathrm{~kg} \mathrm{~h}^{-1}\right)$. After the end of experimentation with uncoated piston and valves the engine was reassembled with 8 YSZ coated piston and valves. In $\mathrm{CE}$, the same experimental procedure was repeated to investigate the effect of TBC on dualfuel engine performance.

\section{Biogas energy share}

Energy share of inducted gaseous fuel greatly depends upon the effective combustion of net fuel energy input to the engine. It depends on quality of the gaseous fuel as well as the engine operating parameters. To attain a definite value of brake power, both inducted fuel (biogas) and pilot fuel (diesel) fulfil the energy demand. The biogas energy share (BGES) can be calculated by Eqs. (1) to (3) [9].

BGES $=\frac{\text { Energy equivalent of biogas }}{\text { Energy equivalent of }(\text { diesel }+ \text { biogas })} \times 100$

Energy equivalent of diesel $=\frac{\dot{\mathrm{m}}_{\text {diesel }} \times \mathrm{CV}_{\text {diesel }}}{3600}$

Energy equivalent of biogas $=\frac{\dot{m}_{\text {biogas }} \times \mathrm{CV}_{\text {biogas }}}{3600}$

where, $\dot{\mathrm{m}}_{\text {diesel }}$ and $\dot{\mathrm{m}}_{\text {biogas }}$ are the mass flow rate of diesel and biogas, CV is the calorific value of the fuels.

\section{Results and discussion}

Experimentations were accomplished to investigate the impact of TBC on engine performance, combustion and emissions of dual-fuel engine using UBG. The deviation of performance parameters like brake specific energy consumption (BSEC), BTE, exhaust gas temperature (EGT), combustion parameters like mean combustion gas temperature (MCT), cylinder pressure and rate of heat release (RHR) and emissions were measured under

Table 3 Specification of the engine

\begin{tabular}{ll}
\hline Make & Kirloskar \\
\hline General details & Diesel Engine test setup 1- cylinder, 4- stroke, Water cooled \\
Rated power & $3.5 \mathrm{~kW}$ at 1500 rpm \\
Speed & $1500 \mathrm{rpm}$ \\
Compression ratio & $18: 1$ \\
Bore & $87.5 \mathrm{~mm}$ \\
Stroke & $110 \mathrm{~mm}$ \\
\hline
\end{tabular}




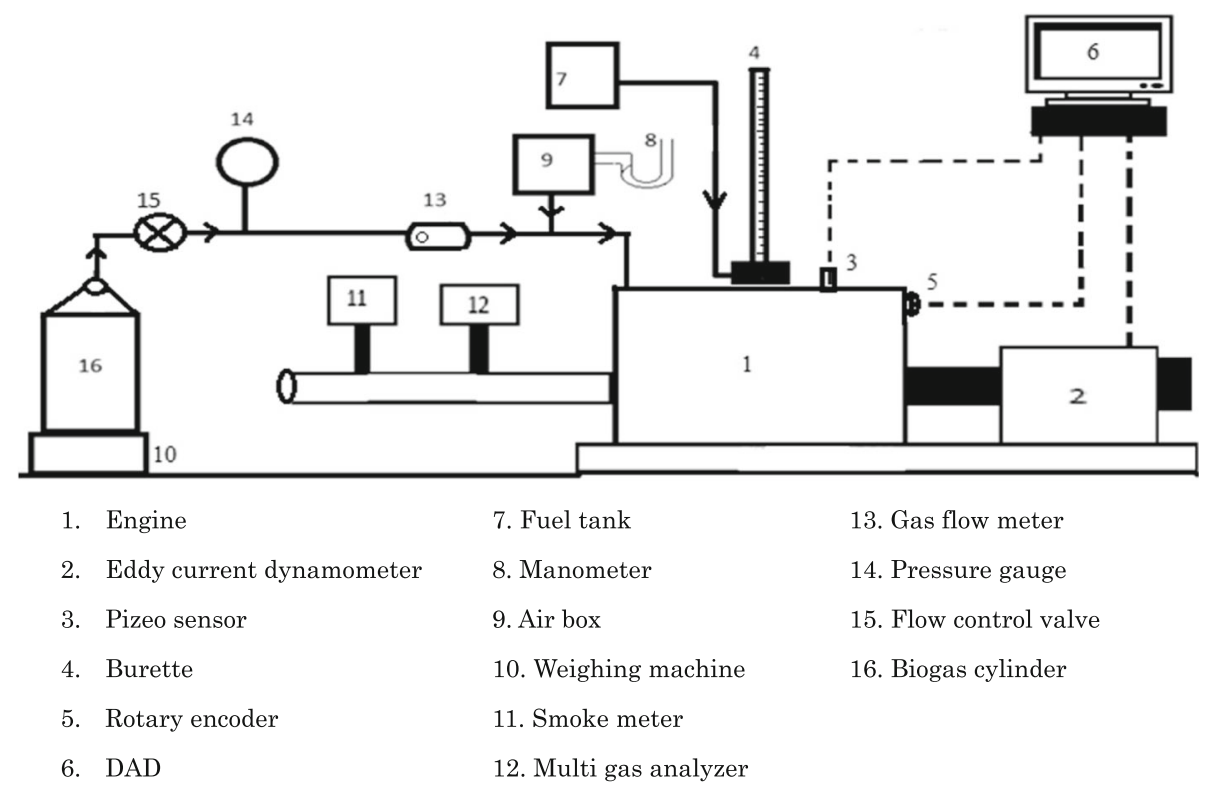

Fig. 1 Block diagram of engine setup

different induction rates of biogas with variation of engine loads.

\section{Performance parameters}

\section{Brake specific energy consumption}

The change in BSEC with variation of engine load for engine with and without TBC at different flow rate of biogas is shown in Fig. 2a. With hike in engine load, BSEC decreased in both modes of operation. This reduction in BSEC can be linked to improvement in combustion quality because of hike in combustion temperature and pressure with increase in engine loads [10]. BSEC increases with increase in biogas substitution because of the lower calorific value of biogas as compared to diesel; it requires increased rate of fuel consumption for the same brake power output. Engine with TBC showed a reduction in BSEC in comparison with uncoated engine, because of increased combustion temperature leading to enhanced energy conversion rate, ensuring the diminution in the energy consumption as compared to uncoated dual-fuel engine [13].

The BSEC at full load operation increased by 23,24 and $30 \%$ for biogas flow rate $0.6,0.8$ and $1 \mathrm{~kg} \mathrm{~h}^{-1}$, respectively. as compared to diesel mode operation, while in CE, the BSEC increased by 8,12 and $18 \%$ for respective biogas flow rates that show a trend of BSEC reaching closer to diesel mode operation with TBC.

\section{BTE}

The change in BTE for coated and uncoated engine with engine load at different flow rates of UBG is shown in
Fig. 2b. It shows that BTE increases with hike in engine load for both diesel and dual-fuel operations. The reason behind this increase is same as that of BSEC as a consequence with improved combustion at elevated temperature resulting in an increase in BTE. However, a decreasing trend of BTE was observed with increase in biogas substitution, as induction of biogas leads to deficit of oxygen in the inhaled charge intake resulting in deficient combustion of the supplied fuel and poor flame propagation of biogas also adds in to the drop of BTE.

It is considerable that in $\mathrm{CE}$, the BTE increases for both modes of operation than that of uncoated engine. This can be related to insulating impact of TBC which minimizes the loss of heat energy leading to an improved combustion. While the increases in combustion temperature and pressure due to coating suppressing the negative impacts of biogas combustion like higher ignition delay, low flame speed as a consequence comparatively higher BTE was observed in dual-fuel operation for CE.

The BTE decreased by 23,29 and $34 \%$ for biogas flow rate $0.6,0.8$ and $1 \mathrm{~kg} \mathrm{~h}^{-1}$, respectively, as compared to base results, whereas in CE, the BTE decreased by 10, 12 and $19 \%$ for respective biogas flow rates at full load operation indicating the improvement in performance in dual-fuel engine with TBC.

\section{EGT}

The variation in EGT for coated and uncoated engine at different engine loads with varying flow rates of UBG is shown in Fig. 2c. The EGT also increases with the hike in engine load, which can be referred to higher fuel 


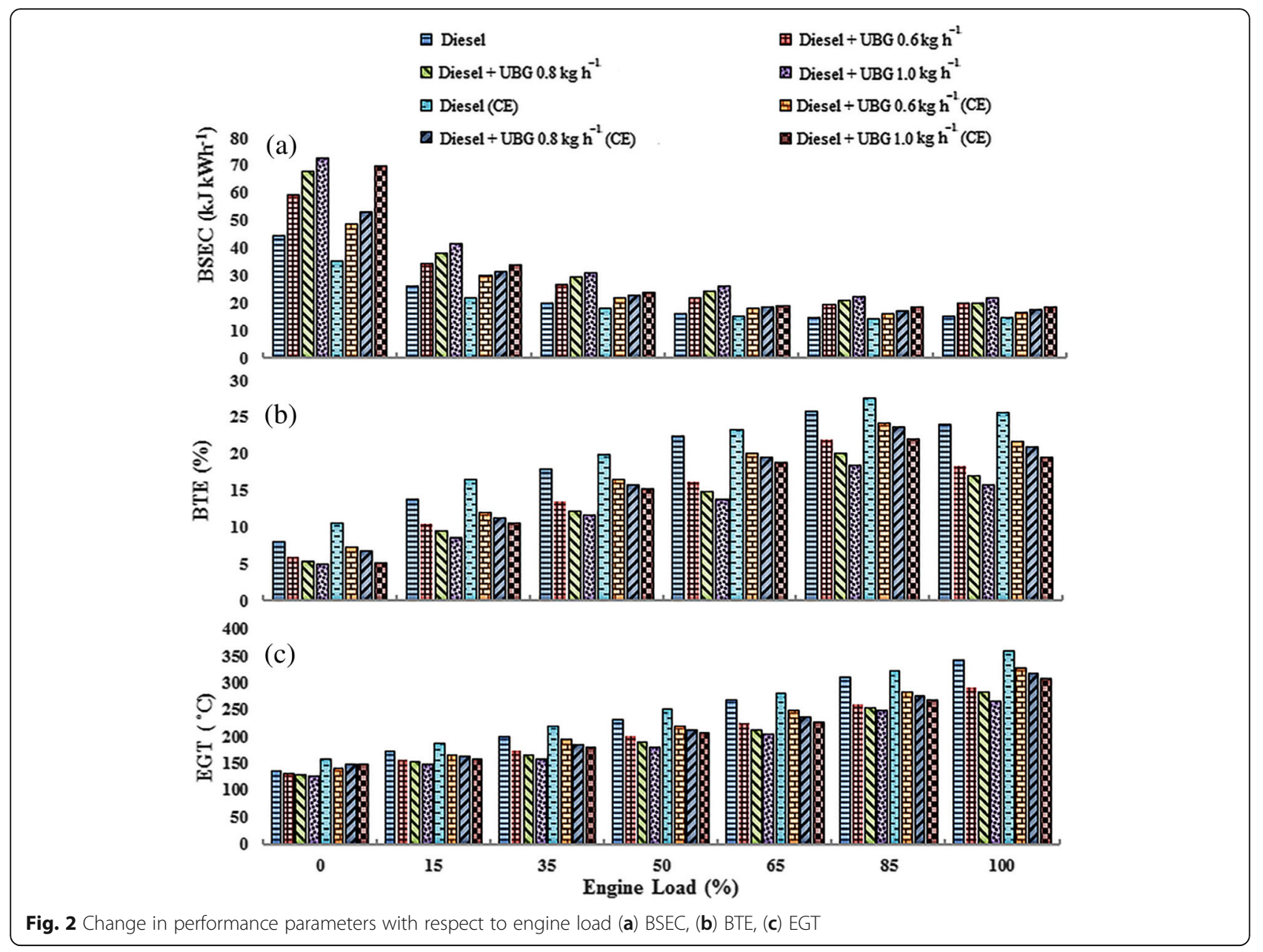

supply to satisfy the demand of brake power leading to a rise in combustion temperature resulting in hike of EGT. Diesel shows higher EGT, or 342 and $360^{\circ} \mathrm{C}$ for uncoated engine and $\mathrm{CE}$, respectively, while with increase in biogas flow rate, EGT gradually decreases. The reason behind this could be due to the fact that the high auto ignition temperature of biogas affects the flame propagation as well as the flame speed, which decreases the mean combustion temperature resulting in reduced EGT as compared to diesel alone operation.

CE indicates a leap in EGT for all modes of operation; this can be referred to the insulating effect of coating that results in hike of combustion temperature leading to improved combustion characteristics which increases the exhaust temperature as compared to uncoated engine operation [15].

The EGT dropped by 14, 17 and $22 \%$ for biogas flow rate $0.6,0.8$ and $1 \mathrm{~kg} \mathrm{~h}^{-1}$, respectively, as compared to diesel mode operation, while in CE, the EGT decreased by 4,6 and $10 \%$ for respective biogas flow rates as compared to base result.

\section{Combustion parameters \\ $M C T$}

The change in MCT with crank angle at full engine load under variation of biogas flow rates is shown in Fig. 3a. With increase in biogas flow rate, the MCT was decreased because the higher heat capacity of biogas decreases the combustion chamber temperature. Again diluting biogas induction that affects the combustion process and presence of $\mathrm{CO}_{2}$ in biogas also affects the in-cylinder temperature negatively that decreases the MCT [9].

MCT of TBC engine increases may be due to the insulating effect that increases thermal resistance within the combustion chamber. This minimizes the heat loss and leads to a more homogeneous combustion that increases MCT. The peak value of MCT for diesel mode operation was recorded to be 1375 and $1390^{\circ} \mathrm{C}$ for uncoated and coated engine, respectively. However, in dual-fuel operation, the peak values of MCT were found to be 1200 , 1215 and $1185^{\circ} \mathrm{C}$ for biogas flow rate $0.6,0.8$ and $1 \mathrm{~kg}$ $\mathrm{h}^{-1}$, respectively, in uncoated engine, while in case of 


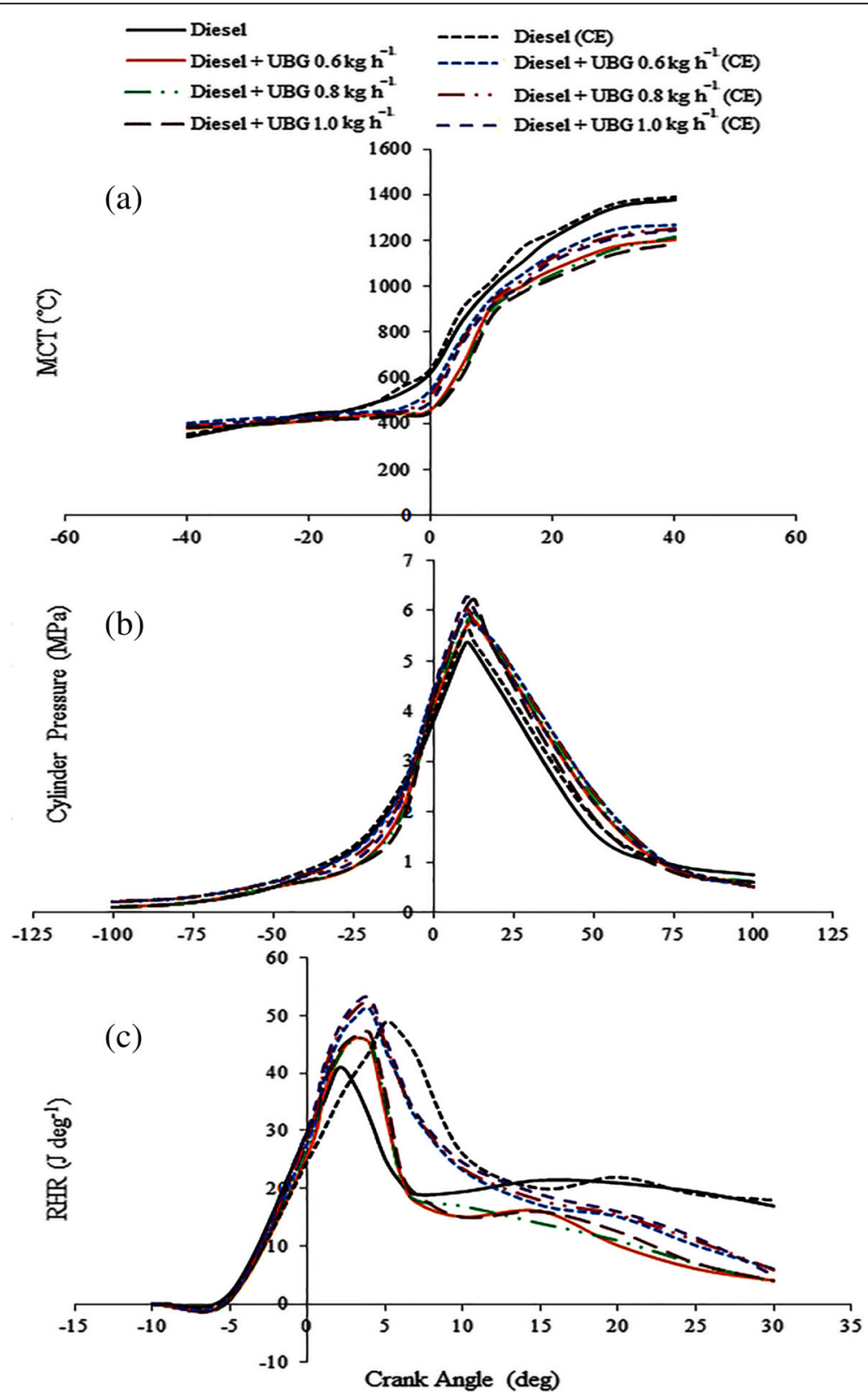

Fig. 3 Change in combustion parameters with engine load (a) MCT, (b) Cylinder pressure, (c) RHR

CE, the MCTs were found to be 1265,1250 and $1245{ }^{\circ} \mathrm{C}$ for respective flow rate of biogas.

\section{Cylinder pressure}

The change in cylinder pressure with respect to crank angle at full engine load is illustrated in Fig. 3b. The peak cylinder pressure rises with increase in biogas flow rate. Presence of biogas with the fresh charge increases the ignition delay, leading to sharp increase in pressure resulting in increased peak cylinder pressure. The peak cylinder pressure for diesel mode operation was recorded to be 5.4
$\mathrm{MPa}$ and for dual-fuel mode it was recorded to be 5.8, 6.0 and 6.2 MPa for biogas flow rate $0.6,0.8$ and $1 \mathrm{kgh}^{-1}$, respectively.

In $\mathrm{TBC}$ engine, an earlier start of combustion can be noticed from the Fig. 3b as the left leg of the pressure curve shows higher slope as compared to pressure curve of uncoated engine in dual-fuel mode operation, indicating the reduction of ignition lag. The graph illustrates that peak pressure for $\mathrm{CE}$ was found to be $5.6 \mathrm{MPa}$ for diesel alone operation while in case of dual-fueled run the peak cylinder pressure was recorded to be 5.9, 6 and 6.3 MPa for respective biogas flow rates. 


\section{RHR}

The changes in RHR with respect to crank angle at full load condition are presented in Fig. 3c. Initially a negative peak was observed for the RHR curve, due to the cooling effect of the injected fuel vaporizing in the combustion chamber resulting in slightly negative RHR during the ignition delay period. An increase in RHR was noticed and the peak value appeared at $2^{\circ}$ after TDC for diesel (41 J deg-1) and $5^{\circ}$ after TDC for diesel in CE (49 J $\left.\operatorname{deg}_{-1}\right)$. The adiabatic effect because of coating enhanced the RHR as compared to uncoated engine, instigating efficient oxidation of the injected fuel. In case of dual-fuel mode, a higher peak of RHR was observed for both coated and uncoated engine. This can be related to improvement in mixture formation of gaseous fuel with inhaled air giving a sudden rise in RHR during premixed combustion stage. The peak value of RHR were found to be 46,46 and $46.5 \mathrm{~J} \mathrm{deg}_{-1}$ for biogas flow rate $0.6,0.8$ and $1 \mathrm{~kg} \mathrm{~h}^{-1}$, respectively, in uncoated engine, while in case of CE, the RHR were found to be 51, 52, and $53 \mathrm{~J}$ $\operatorname{deg}_{-1}$ for respective biogas flow rates. In dual-fuel operation, the second peak of RHR was not prominent like diesel alone operation, as observed in Fig. 3c.

\section{Emission parameters \\ CO emission}

Figure $4 \mathrm{a}$ illustrates that the $\mathrm{CO}$ emissions decrease with increases in engine load, because an increase in ignition centers with higher amount of atomized fuel improves the combustion process at higher engine loads. However, with hike in biogas flow rate, the $\mathrm{CO}$ emissions were increased at all load spectrums. The decreased in-cylinder temperature in dual-fuel operation may be caused by higher heat capacity of inducted biogas along with the deficiency of fresh air which is also responsible for incomplete combustion of the supplied fuel leading to increase in $\mathrm{CO}$ emissions. $\mathrm{CE}$ indicated a drop in $\mathrm{CO}$ emissions for both modes of operation, due to the comparatively higher MCT because coating helped the oxidation of $\mathrm{CO}$ to $\mathrm{CO}_{2}$ which indicates a superior combustion in the dual-fuel engine because of coating [13].

The CO emission at full load operation increased by 35,35 and $40 \%$ for biogas flow rate $0.6,0.8$ and $1 \mathrm{~kg} \mathrm{~h}^{-1}$, respectively, as compared to diesel mode operation, while in engine with TBC, the increase in $\mathrm{CO}$ emission was minimized to 25,28 and $33 \%$ for respective biogas flow rates.

\section{$\mathrm{CO}_{2}$ emission}

The change in $\mathrm{CO}_{2}$ emission with respect to engine load is showed in Fig. 4b. It illustrates that with increase in engine load, $\mathrm{CO}_{2}$ emission increases due to rise in MCT and peak cylinder temperature helped in oxidation of supplied fuel. A decrease of $\mathrm{CO}_{2}$ emission was observed with increases in biogas substitution. The dual-fuel mode operation owing to increase in ignition delay caused by comparatively higher auto-ignition temperature of biogas and slow burning rate of biogas along with deficiency of fresh air, leads to incomplete combustion resulting a drop in $\mathrm{CO}_{2}$ emissions. $\mathrm{CE}$ shows a marginal rise in $\mathrm{CO}_{2}$ emission as compared to base engine. The leap in combustion temperature because of insulating effect of TBC improves the combustion process resulting in increased $\mathrm{CO}_{2}$ emissions.

The $\mathrm{CO}_{2}$ emission decreased by 41,45 and $49 \%$ for biogas flow rate $0.6,0.8$ and $1 \mathrm{~kg} \mathrm{~h}^{-1}$, respectively, as compared to diesel mode operation, while in $\mathrm{CE}, \mathrm{CO}_{2}$ emission decreased by 33, 36 and $38 \%$ for respective biogas flow rates at full load operation.

\section{HC emission}

Unburnt hydrocarbon level arises due to incomplete combustion i.e. partially burnt part of fuel is present in the engine exhaust. The change in $\mathrm{HC}$ emissions at different UBG flow rate is given in Fig. 4c. With increase in engine load, $\mathrm{HC}$ emission decreases, caused by the increase in ignition centers at higher loads owing to increased fuel supply leading to improve the combustion characteristics. However, the $\mathrm{HC}$ emission increases with increasing substitution of biogas due to the reduced volume of intake fresh air that leads to incomplete combustion of inducted fuel. In addition, the fresh mixture trapped in crevice region, escape of fresh charge during valve overlapping also gives rise to $\mathrm{HC}$ emission [9]. In $\mathrm{CE}$, the $\mathrm{HC}$ emission is decreased considerably than that of uncoated engine, because of the rise in combustion temperature during diffusion stage resulting in improved combustion with effective utilization of the intake air leading to superior oxidation of the supplied fuel.

The $\mathrm{HC}$ emission at full load operation increased by 32,43 and $50 \%$ for biogas induction rates $0.6,0.8$ and 1 $\mathrm{kg} \mathrm{h}^{-1}$, respectively, as compared to diesel mode operation, while in $\mathrm{CE}$, the $\mathrm{HC}$ emission increased by 27,31 and $35 \%$ for respective biogas induction rates.

\section{NO emission}

Figure $4 \mathrm{~d}$ exhibits the variation of $\mathrm{NO}$ emission with engine load at different flow rates of biogas. $\mathrm{NO}$ emission mainly depends on oxidation of atmospheric nitrogen at elevated local temperature. It also depends on retention time of elevated temperature and concentration of oxygen in combustion chamber [11]. A decrease in NO emission is noticed with increase in biogas substitution, which may be due to increase in specific molar heat with increase in biogas flow rate that decreases the incylinder temperature during combustion process. Again, 


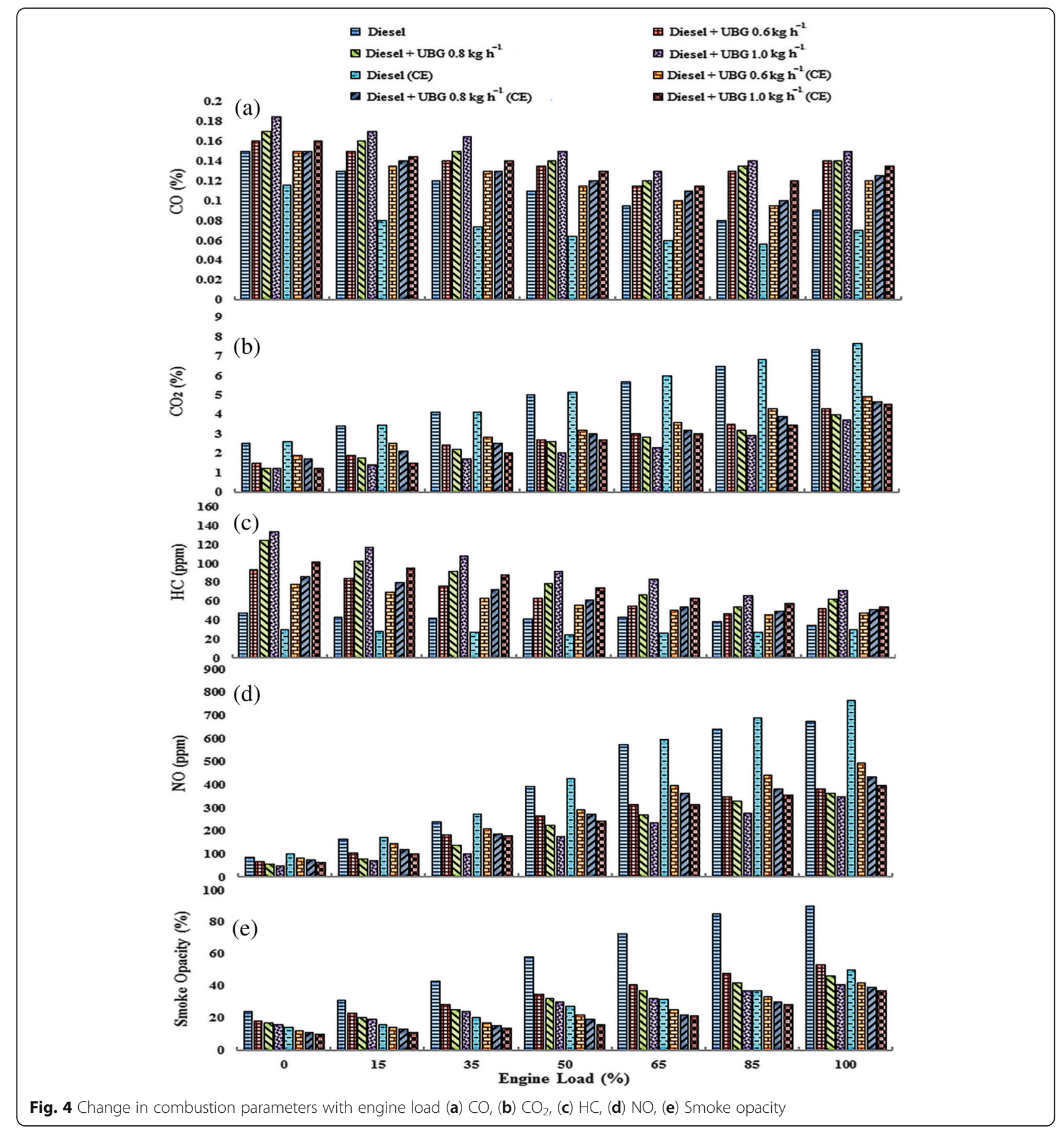

induction of biogas reduces the oxygen content in the combustion chamber and also increases the ignition delay leading to decrease in retention time for NO formation [9]. Increased $\mathrm{NO}$ emission was observed for $\mathrm{CE}$ as compared to uncoated dual-fuel operation; the phenomenon may be caused by the increased combustion temperature that suppresses the ignition delay that serves to comparatively higher RHR in premixed combustion stage leading to increase in $\mathrm{NO}$ emission [16].
At full load engine operation, the NO emission is decreased by 43,46 and $48 \%$ for biogas induction rates 0.6 , 0.8 and $1 \mathrm{~kg} \mathrm{~h}^{-1}$, respectively, as compared to diesel mode operation, while in CE, the NO emission decreased by 26 , 35 and $41 \%$ for respective biogas induction rates.

\section{Smoke opacity}

Figure 4e depicts the change in smoke opacity with engine load at different UBG flow rate. As evidenced from 
the figure, increase in the engine load leads to increases in the smoke opacity, while in dual-fuel mode, smoke opacity decreases showing a considerable difference between diesel alone and dual-fuel operation. This can be attributed to reduction in diesel consumption with increase in biogas flow rate that reduces the aromatic compounds in the fuel air mixture and higher methane content in the supplied biogas has tendency to produce less smoke emissions [17]. TBC has a positive effect on smoke emissions, as the combustion chamber temperature consistently increases because of adiabatic impact of coating leading to decrease in ignition delay that minimizes accumulation of injected fuel and suppresses the formation of fuel reach zone, resulting in enhanced oxidation of soot precursors in the soot forming regions.

At full load engine operation, the smoke opacity is decreased by 41,48 and $54 \%$ for biogas induction rates 0.6 , 0.8 and $1 \mathrm{kgh}^{-1}$, respectively, as compared to diesel mode operation, while in CE, smoke opacity decreased by 53,56 and $58 \%$ for respective biogas induction rates.

\section{Impact of engine load on BGES}

Figure 5 depicts the variation of BGES with engine load at different flow rate of biogas. It is noticed that with hike in engine load, BGES gradually decreases for all tested flow rates of biogas. The energy share strongly depends on calorific value and flow rate of the fuel. Hence, with increase in engine load diesel supply increases leading to decrease in BGES.
At full load engine operation, the BGES was found to be 32,39 and $45 \%$ for biogas induction rates $0.6,0.8$ and $1 \mathrm{~kg} \mathrm{~h}^{-1}$, respectively, as compared to base results, while in CE, the BGESs were 35,46 and $54 \%$ for respective biogas induction rates.

It can be observed that engine with $\mathrm{TBC}$ has shown higher BGES indicating improved combustion process. Comparing the drop in BTE with BGES for different flow rates of biogas at full load condition, biogas flow rate of $0.8 \mathrm{~kg} \mathrm{~h}^{-1}$ for CE shows the best results with high BGES and comparatively lower drop in BTE compared to all other tested conditions.

\section{Conclusions}

The present study was focused on the evaluation of performance and emission characteristics of a dual-fuel engine with TBC at different flow rates $(0.6,0.8$ and $1 \mathrm{~kg}$ $\mathrm{h}^{-1}$ ) of biogas. The following conclusions are observed from the current study:

- Among the three chosen flow rates of biogas in coated as well as uncoated engine, the biogas flow rate of $0.8 \mathrm{~kg} \mathrm{~h}^{-1}$ showed overall suitable results as compared to diesel mode operation of base engine. As BGES for $0.8 \mathrm{~kg} \mathrm{~h}^{-1}$ biogas flow rate was quite higher than that at $0.6 \mathrm{~kg} \mathrm{~h}^{-1}$ biogas flow rate, while the performance and emission characteristics were similar for both the flow rates. Whereas, $1 \mathrm{~kg} \mathrm{~h}^{-1}$ biogas flow rate showed poor engine performance and emission characteristics.

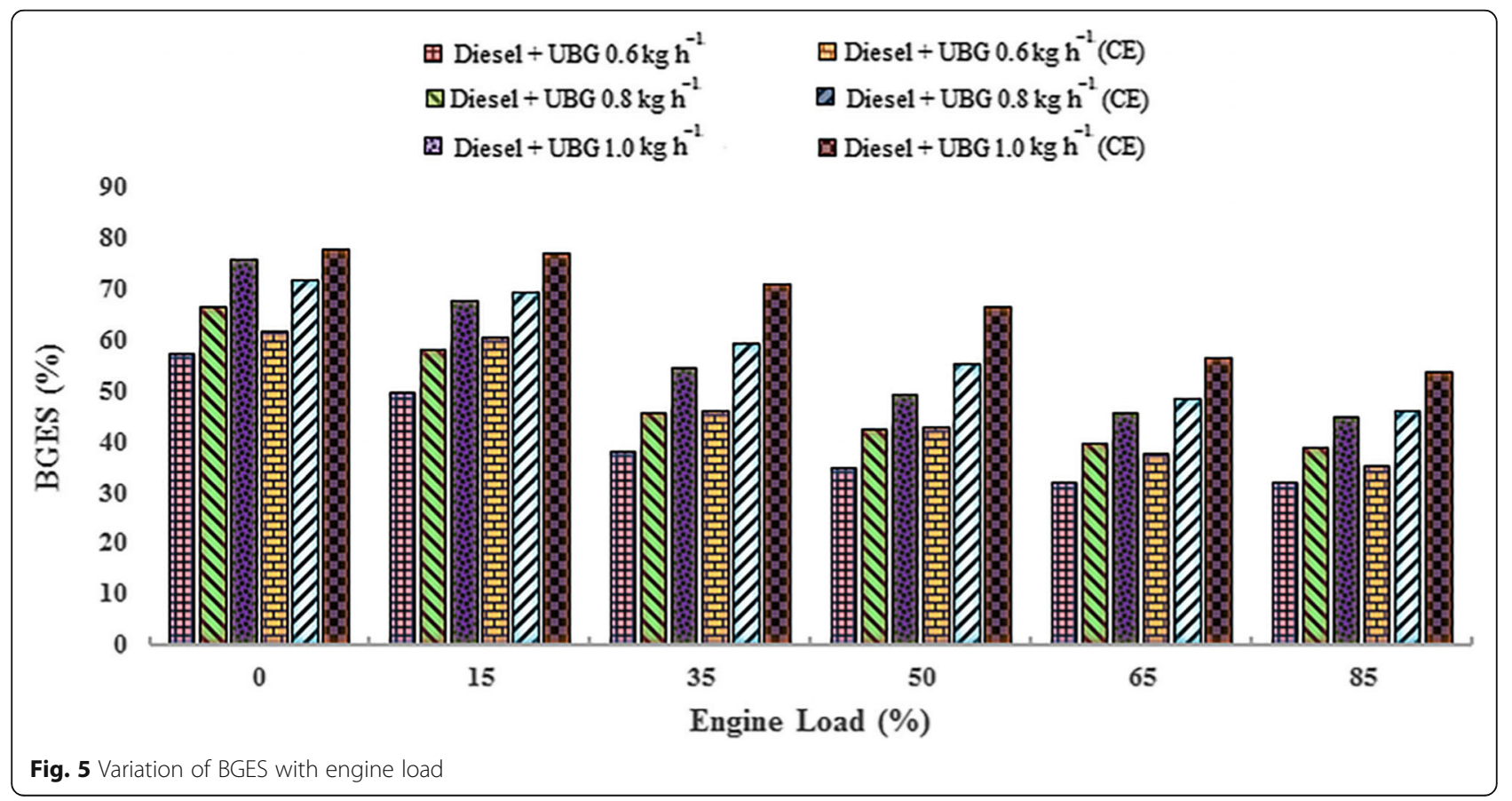


- In dual-fuel mode run, the BTE decreased with increases in biogas flow rate, while application of YSZ coating on engine improved the BTE for all tested biogas flow rates. The biogas flow rate of $0.8 \mathrm{~kg} \mathrm{~h}^{-1}$ showed $12 \%$ drop in BTE as compared to base results.

- Engine emissions like $\mathrm{CO}_{2}, \mathrm{NO}$ and smoke opacity were decreased in dual-fuel mode operation. At $0.8 \mathrm{~kg} \mathrm{~h}^{-1}$ biogas flow rate, 36,35 and $56 \%$ decrease in $\mathrm{CO}_{2}$, NO and smoke opacity, respectively. While dual-fuel operation in $\mathrm{CE}$ showed comparatively higher $\mathrm{CO}_{2}$ and $\mathrm{NO}$ emissions than uncoated engine.

- $\mathrm{CO}$ and $\mathrm{HC}$ emissions were increased for dual-fuel mode operation as compared to diesel mode operation. However, $0.8 \mathrm{~kg} \mathrm{~h}^{-1}$ biogas flow rate showed $28 \%$ rise in $\mathrm{CO}$ emissions and $31 \%$ higher $\mathrm{HC}$ emissions as compared to diesel alone operation in uncoated engine.

- Biogas substitution with $0.8 \mathrm{~kg} \mathrm{~h}^{-1}$ flow rate in CE yielded the optimized results in terms of BTE with $46 \%$ BGES at full load. Further increase in biogas flow rate showed a higher drop in BTE with considerable increases in $\mathrm{HC}$ and $\mathrm{CO}$ emission.

On account of the presented results, it is concluded that $\mathrm{CI}$ engine with 8YSZ coating provides encouraging results regarding engine performance, combustion and reduction of various emissions from dual-fuel engines. Further research works are needed to reduce the HC and $\mathrm{CO}$ emissions in dual-fuel run by adapting supercharging technique or application of fuel additives to improve the combustion process.

\section{Acknowledgements}

Not applicable.

\section{Authors' contributions}

SKA defined and guided the whole experimentation; SPJ processed and analyzed the experimental observations. Both authors read and approved the final manuscript.

\section{Funding}

The authors have not received funding from any source in the present research work.

\section{Availability of data and materials}

All data generated or analyzed during this study are recorded from experimentation.

\section{Competing interests}

The author(s) declared no potential conflicts of interest with respect to the research, authorship, and/or publication of this article.

Received: 10 April 2019 Accepted: 12 August 2019

Published online: 06 September 2019

\section{References}

1. Jena SP, Acharya SK, Deheri C. Thermodynamic analysis of a twin cylinder diesel engine in dual fuel mode with producer gas. BiofuelsUK. 2016;7:49-55.
2. Bora BJ, Saha UK, Chatterjee S, Veer V. Effect of compression ratio on performance, combustion and emission characteristics of a dual fuel diesel engine run on raw biogas. Energ Convers Manage. 2014;87:1000-9.

3. Jena SP, Mishra S, Acharya SK, Mishra SK. An experimental approach to produce biogas from semi dried banana leaves. Sustain Energy Technol Assess. 2017;19:173-8.

4. Acharya SK, Jena SP. Performance and emission analysis of a $\mathrm{Cl}$ engine in dual mode with LPG and Karanja oil methyl ester. ISRN Renew Energ. 2013; 2013:540589.

5. Duc PM, Wattanavichien K. Study on biogas premixed charge diesel dual fuelled engine. Energ Convers Manage. 2007:48:2286-308.

6. Makareviciene V, Sendzikiene E, Pukalskas S, Rimkus A, Vegneris R. Performance and emission characteristics of biogas used in diesel engine operation. Energ Convers Manage. 2013;75:224-33.

7. Tippayawong N, Promwungkwa A, Rerkkriangkrai P. Long-term operation of a small biogas/diesel dual-fuel engine for on-farm electricity generation. Biosyst Eng. 2007;98:26-32.

8. Ambarita H. Performance and emission characteristics of a small diesel engine run in dual-fuel (diesel-biogas) mode. Case Stud Therm Eng. 2017; 10:179-91.

9. Barik D, Murugan S. Investigation on combustion performance and emission characteristics of a DI (direct injection) diesel engine fueled with biogasdiesel in dual fuel mode. Energy. 2014;72:760-71.

10. Barik D, Murugan S. Experimental investigation on the behavior of a DI diesel engine fueled with raw biogas-diesel dual fuel at different injection timing. J Energy Inst. 2016:89:373-88.

11. Verma S, Das LM, Kaushik SC. Effects of varying composition of biogas on performance and emission characteristics of compression ignition engine using exergy analysis. Energ Convers Manage. 2017;138:346-59.

12. Aydin S, Sayin C, Altun S, Aydin H. Effects of thermal barrier coating on the performance and combustion characteristics of a diesel engine fueled with biodiesel produced from waste frying cottonseed oil and ultra-low sulfur diesel. Int J Green Energy. 2016;13:1102-8.

13. Jena SP, Acharya SK, Das HC, Patnaik PP, Bajpai S. Investigation of the effect of $\mathrm{FeCl}_{3}$ on combustion and emission of diesel engine with thermal barrier coating. Sustain Environ Res. 2018;28:72-8.

14. Sivakumar G, Kumar SS. Investigation on effect of Yttria stabilized zirconia coated piston crown on performance and emission characteristics of a diesel engine. Alex Eng J. 2014;53:787-94.

15. Mohapatra D, Swain RK, Jena SP, Acharya SK, Patnaik PP. Effect of steam injection and $\mathrm{FeCl}_{3}$ as fuel additive on performance of thermal barrier coated diesel engine. Sustain Environ Res. 2018;28:247-55.

16. Heywood JB. Internal combustion engine fundamentals. 1st ed. New York: McGraw-Hill; 1988

17. Yilmaz IT, Gumus M. Investigation of the effect of biogas on combustion and emissions of TBC diesel engine. Fuel. 2017;188:69-78.

\section{Publisher's Note}

Springer Nature remains neutral with regard to jurisdictional claims in published maps and institutional affiliations. 